\title{
Flutamide treatment in severe acne in women-still controversial
}

\author{
Alina Urma*, Liliana Foia**, Brzezinski Piotr***, Anca Chiriac**** \\ *Emergency Hospital for Children "Saint Mary" Iasi, Romania, ,**University of Medicine and Pharmacy "Gr T Popa” Iasi, Romania, \\ ***6th Military Support Unit Hospital, Dermatology, Ustka, Poland, ${ }^{* * * * * *}$ University Apollonia, Nicolina Medical Center, Iasi. Romania
}

Guidelines recommend hormonal treatment in severe acne, in forms of acne with no response to standard therapeutical options, in women with proved hyperandrogenism. Hormonal therapy for acne includes oral contraceptives; anti-androgens, such as cyproterone acetate, spironolactone and flutamide; low-dose glucocorticoids and gonadotropin-releasing hormone agonists.

In daily practice there are many cases with moderate to severe forms of acne, in young women without any clinical or hormonal abnormalities, who do not respond to systemic antibiotics, associated with topical antibiotics, azelaic acid, tretinoin, benzoyl peroxide or combinations.

We performed a study on 44 young women, with age ranging from 17 to 37 years, with non-responding severe forms of acne after 6 months of therapy.

Endocrine examination was done at the beginning of the study measuring: testosterone levels, BMI, calculating Ferriman hirsutism score and evaluating liver function.

Out of 44 patients only 6 patients (13.4\%) had high levels of testosterone and no other lab abnormal parameters. We presumed a high affinity of androgen receptors to normal level of testosterone and antiandrogen treatment was started.

Hormonal therapy was performed for 6 consecutive months using different schemas such as: only flutamide $125 \mathrm{mg} /$ day in 27 cases; flutamide $125 \mathrm{mg} /$ day associated with spironolactone $100 \mathrm{mg} /$ day and metforfim $500 \mathrm{mg} /$ day in 3 cases; flutamide $125 \mathrm{mg} /$ day plus utrogestan $100 \mathrm{mg} /$ day and metformin $500 \mathrm{mg} /$ day in 1 case; flutamide $125 \mathrm{mg} /$ day and spirolonactone $50 \mathrm{mg} /$ day in 6 cases; flutamide $125 \mathrm{mg} /$ day and metformin $500 \mathrm{mg} /$ day in 7 cases. The same topical anti acne treatment was associated in each case: azelaic acid and erythromycin plus tretinoin applied daily.

Good tolerability and no side effects have been declared.

Despite different association of hormonal therapy clearing of acne was achieved at the end of 6 months of treatment with no difference, but in all cases rebounds were observed after withdraw the hormonal therapy, despite the maintenance of the topical treatment. 